\title{
The Significance Of Teaching Perspectives Among Academic Disciplines
}

David M. Deggs, University of Arkansas, USA

Krisanna L. Machtmes, Louisiana State University, USA

Earl Johnson, Louisiana State University, USA

\begin{abstract}
This study examined the teaching perspectives among faculty from a research extensive university in the southern United States. A simple random sample was drawn from the institution's faculty, and a total of $n=131$ responded to the survey. Respondents were asked to complete the Teaching Perspectives Inventory via the Internet and complete a demographic survey. The Analysis of Variance procedure was used to determine if dominant teaching perspectives were disciplinespecific. The results of this analysis concluded that a significant difference existed among respondents, with Apprenticeship as a dominant teaching perspective $[F(12,118)=2.036, p=$ $.027]$.
\end{abstract}

Keywords: teaching perspectives (inventory), personal theories of teaching and learning, web-based/electronic surveys

\section{INTRODUCTION}

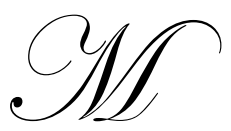

ost higher education faculty strive to become more effective teachers so that students can learn better, and many explore methods to improve their teaching practice. Higher education faculty do not ordinarily receive training as teachers, which is often attributed to the fact that graduate programs have not traditionally included courses on leading a class. This is because graduate programs have focused on the advancement of content knowledge and have not generally allowed for the synthesis between content knowledge and teaching pedagogy (Bartlett, 2005; Cambridge, 1999; Kreber, 2001). The focus on content knowledge relative to the discipline begs questions about how the perspectives of faculty in different disciplines.

Perhaps Menges (2000) best summarizes current knowledge and understanding of faculty roles related to teaching. Menges stated that we know much about what faculty members do as teachers, including how time is spent, teaching goals, and instructional methods (including how they are influenced by other variables and their consistency over time). However, some questions remain such as, "How do they [teachers] derive personal theories of teaching and learning?" (Menges, 2000, p. 7). This study sought to further explore those personal theories of teaching and learning among faculty utilizing the Teaching Perspectives Inventory.

\section{LITERATURE REVIEW}

Teaching perspective is defined by Pratt and Associates (1998) as what we "do as teachers and why we think such actions are worthy and justified" (Pratt \& Associates, 1998, p.10). The five perspectives on teaching include Transmission, Apprenticeship, Developmental, Nurturing, and Social Reform. Teaching perspectives are not synonymous with teaching styles. Teaching perspectives are more innate, as Pratt stated:

Each perspective on teaching is a complex web of actions, intentions and beliefs; each, in turn, creates its own criteria for judging or evaluating right and wrong, true and false, effective and ineffective. Perspectives determine our roles and idealized self-images as teachers as well as the basis for reflecting on practice. (Pratt \& Associates, 1998, p. 35) 
Teachers who exemplify the Transmission perspective are assumed to have a high degree of mastery of subject matter. Effective Transmission teachers "make efficient use of class time, clarify misunderstandings, answer questions, provide timely feedback, correct errors, provide reviews, summarize what has been presented, direct students to appropriate resources, set high standards for achievement and develop objective means of assessing learning" (Pratt \& Collins, n.d., para. 1).

Teachers who subscribe to the Apprenticeship perspective "must reveal the inner workings of skilled performance and must now translate it into accessible language and an ordered set of tasks" (Pratt \& Collins, n.d., para. 2). Through the learning process, teachers start with simple and move to complex tasks. The role of the Apprenticeship teacher changes as the learner masters content, so that the learner assumes more responsibility.

The Developmental perspective is founded in the notion that teaching is planned and focused from the learner's point of view. Effective Developmental teachers "understand how their learners think and reason about the content" (Pratt \& Collins, n.d., para. 3) and teach with the primary goal of "helping learners develop increasingly complex and sophisticated cognitive structures for comprehending the content" (Pratt \& Collins, n.d., para. 3). This is done by questioning learners in simple to more complex content, and offering meaningful examples for the learner.

Teachers with the Nurturing perspective make a "long-term, hard, persistent effort to achieve [which] come from the heart, as well as the head" (Pratt \& Collins, n.d., para. 4). Nurturing teachers feel that they can affect learners because students "can succeed at learning if they give it a good try; their achievement is a product of their own effort and ability, rather than the benevolence of a teacher; and their efforts to learn will be supported by their teacher and their peers" (Pratt \& Collins, n.d., para. 4).

Finally, the Social Reform perspective is focused on "Effective teaching [that] seeks to change society in substantive ways" (Pratt \& Collins, n.d., para. 5). Social Reform teachers are concerned with the "awakening of students to values and ideologies that are embedded in texts and common practices within their discipline" (Pratt \& Collins, n.d., para. 5).

A greater understanding of teaching perspectives is embedded in the understanding of the indicators of commitment, or the actions, intentions, and beliefs that frame each teaching perspective. Actions are described as the "routines and techniques we use to engage people in content" (Pratt \& Associates, 1998, p. 17). Actions are the most concrete and accessible aspect of a teaching perspective, and are the means through which we activate intentions and beliefs to help people learn. "Intentions are general statements that point toward an overall agenda of purpose" (Pratt \& Associates, 1998, p. 18). The intention of the teacher is the "teacher's statement of purpose, responsibility, and commitment directed toward learners, content, context, ideals, or some combination of these" (Pratt \& Associates, 1998, p. 18). Beliefs are the final aspect of understanding teaching perspectives. As the most abstract aspect, beliefs represent underlying values which are held to varying degrees of meaning among people. Beliefs about knowledge determine what is to be taught and what evidence will be accepted that the knowledge has been taught. Beliefs represent the most stable and least flexible aspect of a person's perspective on teaching (Pratt \& Associates, 1998).

Teaching perspectives are different than teaching styles. "Our teaching style represents those enduring personal qualities and behaviors that appear in how we conduct our classes" (Grasha, 2002, p. 1). One of the most recognized works on teaching style is Grasha's (2002) work, Teaching With Style, in which he stated that "identifying the elements of our styles as teachers has proved to be difficult" (Grasha, 2002, p. 1), and that "no clear consensus about the common components of style" exists (Grasha, 2002, p. 1). Amongst the themes and variations offered by Grasha, are the general modes of classroom behavior, characteristics of popular teachers, behaviors common to all faculty, various roles that teachers play, and personality traits (Grasha, 2002, p. 38-39). Grasha rightfully stated that "information about teaching style is only one-half the teacher-student interaction" (Grasha, 2002, p. 41). 
Teachers often adopt teaching styles, or roles in the classroom, that feel right in a given teaching situation. Although there are many "natural" or "born" teachers that fill the classrooms and provide instruction, there is not one best way to be a teacher. Furthermore, Cranton defined teaching style as "a product of our vision or philosophy of education and our practical responses to contexts and students" (Cranton, 1994, p. 1). The beliefs, values, and assumptions about teaching which teachers hold are revealed in their teaching style, which may be influenced by the content taught. Cranton offered the example of teaching statistics and adult education, where the teaching philosophy is the same, but different methods and techniques are employed to teach the two different respondents in a somewhat different style (Cranton, 1994).

\section{METHOD}

The first objective of this study was to describe the dominant teaching perspective of higher education faculty, as measured by the Teaching Perspective Inventory (TPI). The categories measured by the TPI include Transmission, Apprenticeship, Developmental, Nurturing, and Social Reform.

The second objective of this study was to compare the dominant teaching perspective of higher education faculty by the academic college or school in which the faculty member holds his or her teaching appointment. The colleges and schools of the institution in which this study was conducted include Agriculture, Art \& Design, Arts \& Sciences, Basic Sciences, Business Administration, School of the Coast and Environment, Education, Engineering, Library \& Information Science, Mass Communication, Music \& Dramatic Arts, Social Work, and Veterinary Medicine.

The primary data collection instrument used in this study was the Teaching Perspective Inventory (TPI), which was developed "through successive stages of operationalizing Pratt's five perspectives into five separate scales concerning actions, intentions and beliefs related to teaching" (Pratt, Collins \& Selinger, 2001, Instrument Development section, para 1). The most recent version of the TPI included 45 items which were tested on more than 25 groups, totaling over 1,000 respondents - including teachers of adults in law, pharmacy, dietetics, workforce training, nursing, industry, and fitness, as well as adult education graduate students in the United States, Canada, and Singapore. Reliability of the data from the subscale was found to be high: Transmission (.81); Apprenticeship (.88); Developmental (.85); Nurturance (.92); and Social Reform (.82). The TPI provides respondents with one (and sometimes two) dominant teaching perspectives. A dominant perspective is considered one standard deviation or more above an individual's personal mean, which is the mean of all five of their TPI scores (Pratt et al., 2001).

The frame for this study included assistant professors, associate professors, and professors whom have been granted tenure or whom are in a tenure-track position at the institution in which this study was conducted, with at least a $10 \%$ or higher teaching load. The frame of the accessible population was identified through personnel records at the institution in which this study was conducted. A simple random sample of $N=536$ was drawn from the population of $\mathrm{N}=890$ faculty at this institution. Cochran's sample size determination Formula for $n$ With Continuous Data (Cochran, 1977), was used to determine the minimum sample size. To ensure that adequate data were collected, the sample size was doubled from 268 to 536.

\section{DATA COLLECTION}

Arrangements were made for the electronic delivery of data collected through the web-based version of the Teaching Perspective Inventory (TPI). The developers of the TPI placed a button on the instrument's webpage so that data collected from this study could be separated from other data collected on the website. Data collected from participants in this research study were sent by instrument developers in an unprocessed format to the researchers.

Follow-up postcards were sent to those individuals whom did not respond to the initial survey mailing, two weeks after the first survey questionnaire had been sent, to request a response in accordance with the procedures developed by Dillman and Salant (1994). A follow-up letter was sent one month after the initial survey questionnaire was sent, along with a replacement questionnaire and return self-addressed envelope. The decision was made to not include any questionnaire received six weeks after the initial survey was sent. A total of $n=131$ 
(24.4\%) subjects (out of a sample of $N=536$ ) responded to this survey throughout the three (3) waves of data collection.

To minimize non-response error, the procedures established by Lindner et al. (2001) were followed. Twenty (20) non-respondents were randomly selected and contacted via telephone for inclusion in a follow-up survey, and were asked to respond to 10 randomly selected items from the demographic survey instrument. The data collected from these non-respondents were statistically compared to the data from the respondents for these 10 items.

It was decided $a^{\prime}$ priori that, if statistically significant differences were found in more than two scale items, it would be concluded that responders differed from non-responders. The chi-square analysis found no statistically significant differences in any of the 10 items from the demographic survey instrument; therefore, it was concluded that there were no statistically significant differences between the responders and non-responders.

\section{FINDINGS}

The first objective of this study was to describe the dominant teaching perspective of higher education faculty at the institution in which this study was conducted, using the results of the TPI [as developed by Pratt and Collins (Pratt and Collins, 2001)]. A majority of study respondents $(n=95,72.5 \%)$ had one dominant teaching perspective. The dominance of teaching perspectives is outlined in Table 1.

Table 1

Dominance of Teaching Perspectives

\begin{tabular}{lll}
\hline & Number & Percent \\
\hline Teaching Perspectives & & \\
$\begin{array}{l}\text { One Dominant } \\
\text { Perspective }\end{array}$ & 95 & 72.5 \\
$\begin{array}{l}\text { Two or More Dominant } \\
\text { Teaching Perspectives }\end{array}$ & 5 & 3.8 \\
$\begin{array}{l}\text { No Dominant } \\
\text { Teaching Perspectives }\end{array}$ & 31 & 23.7 \\
\hline Total & 131 & 100.0 \\
\hline
\end{tabular}

The second objective of this study was to compare the dominant teaching perspective of higher education faculty by the academic college or school in which the faculty member holds his or her teaching appointment at the institution in which this study was conducted. The analysis of variance (ANOVA) procedure was used to compare the dominant teaching perspective by the academic college or school in which the faculty member holds their teaching appointment. A significant $\mathrm{F}$ value $[F(12,118)=2.036, \mathrm{p}=.027]$ was found among the colleges and schools, indicating that there was a statistically significant difference amongst the colleges and schools on the dominant teaching perspectives of the faculty.

Tukey's Post-hoc Multiple Comparison test was used to specifically determine which colleges or schools were different. Results indicated that faculty with "Apprenticeship" as dominant teaching perspectives were statistically different among the colleges and schools of the institution where this study was conducted. Table 2 presents the means and standard deviations of the total teaching perspective scores by academic college, and Table 3 represents the result of the ANOVA. 
Table 2

Means and Standard Deviations of Total Teaching Perspective Scores

\begin{tabular}{lccc}
\hline $\begin{array}{l}\text { Academic } \\
\text { College or School }\end{array}$ & n & M & SD \\
\hline Agriculture & 24 & 32.3 & 3.1 \\
Art \& Design & 8 & 34.7 & 4.8 \\
Arts \& Sciences & 25 & 30.8 & 3.5 \\
Basic Sciences & 17 & 31.6 & 3.3 \\
Business Administration & 9 & 31.3 & 2.4 \\
Coast \& Environment & 3 & 30.0 & 3.0 \\
Education & 7 & 31.1 & 3.5 \\
Engineering & 12 & 31.7 & 5.6 \\
Library \& Information Science & 3 & 33.5 & 1.7 \\
Mass Communication & 2 & 35.0 & 1.4 \\
Music \& Dramatic Arts & 10 & 34.4 & 3.4 \\
Social Work & 4 & 36.2 & 1.8 \\
Veterinary Medicine & 7 & 29.7 & 2.4 \\
\hline Total ${ }^{a}$ & 131 & 32.0 & 3.7 \\
\hline${ }^{a}$ Reported as overall mean and standard deviation. & & \\
\hline
\end{tabular}

Table 3

Analysis of Variance for Dominant Teaching Perspective

\begin{tabular}{lcccc}
\hline Source & $\boldsymbol{d} \boldsymbol{f}$ & $\boldsymbol{M S}$ & $\boldsymbol{F}^{\mathbf{a}}$ & $\boldsymbol{p}^{\mathbf{b}}$ \\
\hline Between Groups & 12 & 25.785 & 2.036 & .027 \\
Within Groups & 118 & 12.662 & & \\
Total & 130 & & & \\
\hline
\end{tabular}

Note. Groups were the academic colleges and schools of the institution in which this study was conducted for the sample $(n=131)$.

${ }^{a}$ One-Way Analysis of Variance.

${ }^{\mathrm{b}} .05$ Alpha Level for the 2-Tailed Test of Significance.

\section{RESULTS AND CONCLUSIONS}

Pratt and Associates (1998) stated that faculty members have personal epistemologies, which represent beliefs of knowledge, learning, and evaluation of learning. These personal epistemologies serve as a basis for 
validating one's personal truth. The teaching process requires the faculty member to constantly consider their personal epistemology (Pratt \& Associates, 1998).

A majority of study respondents $(n=95,72.5 \%)$ had one dominant teaching perspective. Five $(n=5$, $3.8 \%)$ study respondents had two or more dominant teaching perspectives, and a total of thirty-one $(n=31,23.7 \%)$ faculty had no dominant teaching perspective.

The number of respondents with one dominant teaching perspective in this study $(72.5 \%)$ is similar to the results of a study conducted by Collins et al. (n.d.), where a total of 356 students seeking secondary teaching certification completed an earlier on-line version of the Teaching Perspective Inventory. The results of their study found that $70.5 \%$ of the respondents had one dominant teaching perspective.

This study found that $3.8 \%$ of respondents had two or more dominant teaching perspectives; however, Collins et al. found that $25.8 \%$ of the respondents in their sample had two or more dominant teaching perspectives. This study found that $23.7 \%$ of respondents had no dominant teaching perspective, while Collins et al. found that $3.4 \%$ of their respondents had no dominant teaching perspective.

These results would support the notion that dominance of one teaching perspective may be typical; however, the results from Collins et al. cannot be compared to this study because it included secondary teachers and this study included postsecondary faculty. Furthermore, the results for two or more dominant perspectives versus no dominant perspective are inverted for the two studies. This may perhaps demonstrate the differences between the discipline-specific epistemologies of secondary versus postsecondary faculty.

This study also compared the dominant teaching perspective of higher education faculty, and the academic college or school in which the faculty member holds his or her teaching appointment. The results of this analysis concluded that a statistically significant difference existed among faculty with "Apprenticeship" as a dominant teaching perspective $[F(12,118)=2.036, \mathrm{p}=.027]$. However, this finding should be applied judiciously given the small delivered sample size $(n=131,24.4 \%)$.

Dinham (1996) suggested that teaching perspectives might be related to the academic field. Dinham stated, "The field not only represents an academic specialization, it also provides the lens through which the academic views life itself. The discipline thus influences teaching not only in selection of course content but in the teacher's very thinking" (Dinham, 1996, p. 303). This was confirmed in only the "Apprenticeship" perspective in this study.

When considering how teaching perspectives are derived among the other four perspectives, perhaps McKeachie (1999) offers the best explanation:

We develop values by observing and modeling ourselves after others and testing out our values in thought and words and action. Teachers are significant models, and teacher behavior is important, both as it models values and as teachers create situations in which the expression of values becomes salient. (McKeachie, 1999, p. 344)

Based upon McKeachie's statement, as found with the other four perspectives in this study, the discipline-specific epistemologies do not affect teaching perspectives.

The results of this study did not yield a conclusive response for the question posed by Menges (2000) related to how faculty derive personal theories of teaching and learning. Further research should be conducted to explore personal theories of teaching and learning among higher education faculty, especially related to how faculty derive personal theories of teaching and learning and why those actions are worthy and justified.

\section{AUTHOR INFORMATION}

Dr. David Deggs is an Assistant Professor of Workforce Development Education at the University of Arkansas in Fayetteville. Prior to joining the University of Arkansas he was program director for Louisiana Campus Compact, a 
statewide organization of presidents and chancellors dedicated to promoting service-learning and civic engagement in postsecondary education. Dr. Deggs previously administered Louisiana's adult education and GED Testing programs at the Louisiana Department of Education. He earned his Ph.D. at Louisiana State University and Agricultural \& Mechanical College and his master's and bachelor's degrees at Northwestern State University of Louisiana.

Dr. Krisanna L. Machtmes is an Associate Professor in the School of Human Resource Education and Workforce Development at the Louisiana State University and A\&M College, where she teaches graduate-level courses in research methods, evaluation, and distance learning. She received her Ph.D. in curriculum and instruction from the Purdue University and worked as an evaluator for the Purdue University Four-H department. Dr. Machtmes serves as a peer reviewer for several journals and associations related to research methods and evaluation, and has published numerous articles in peer-reviewed journals.

Dr. Earl Johnson began his Cooperative Extension Service career as an assistant county agent with Auburn University, with responsibility in both 4-H youth development and adult agriculture programs. After receiving the $\mathrm{Ph} . D$. degree in Vocational Education from Louisiana State University, he worked briefly as an Extension specialist for the University of Georgia. Dr. Johnson then returned to LSU as an Extension programming specialist, and also taught on an adjunct basis with the LSU School of Human Resource Education and Workforce Development, retiring as a professor in 2008 .

\section{REFERENCES}

1. Bartlett, T. (2005, February 11). Please take my advice: 5 books for professors who want to improve their teaching. The Chronicle of Higher Education LI (23), p. A14.

2. Cambridge, B. (1999). The scholarship of teaching and learning: Questions and answers from the field. American Association of Higher Education Bulletin.

3. $\quad$ Cochran, W.G. (1977). Sampling Techniques. New York: John Wiley and Sons.

4. Collins, J.B., Selinger, S.J., \& Pratt, D.D. (n.d.). How do perspectives on teaching vary across disciplinary majors for students enrolled in teacher preparation? Retrieved October 10, 2004 from http://www.teachingperspectives.com

5. Dillman, D.A. \& Salant, P. (1994). How to conduct your own survey. New York: John Wiley and Sons.

6. Dinham, S.D. (1996). What college teachers need to know. In R. J. Menges, M. Weimer \& Associates (Eds.). Teaching on solid ground. (pp. 297-313). San Francisco: Jossey-Bass.

7. Grasha, A. F. (2002). Teaching with style. San Bernadino, CA: Alliance Publishers.

8. Kreber, C. (2001). The scholarship of teaching and its implementation in faculty development and graduate education. New Directions for Teaching and Learning 86, 79-88.

9. Lindner, J.R., Murphy, T.H., \& Briers, G.E. (2001). Handling nonresponse in social science research. Journal of Agricultural Education Research 42(4), 43-53.

10. McKeachie, W. J. (1999). McKeachie's teaching tips: Strategies, research, and theory for college and university teachers. (10th ed.). Boston: Houghton Mifflin.

11. Menges, R. (2000). Shortcomings of research on evaluating and improving teaching in higher education. New Directions for Teaching and Learning 83, 5-11.

12. Pratt, D.D. \& Associates (1998). Five Perspectives on Teaching in Adult and Higher Education. Malabar, FL: Krieger Publishing Company.

13. Pratt, D.D. \& Collins, J.B. (2001). Teaching perspectives inventory. Retrieved May 14, 2005, from http://www.teachingperspectives.com/

14. Pratt, D.D., Collins, J.B., \& Selinger, S.J. (2001). Development and use of the Teaching Perspectives Inventory (TPI). Paper presented at the 2001 American Educational Research Association Annual Meeting, Seattle, WA. Retrieved May 14, 2005, from http://www.teachingperspectives.com/PDF/development1.pdf

15. Pratt, D.D. \& Collins, J.B. (n.d.) Summaries of five teaching perspectives. Retrieved May 14, 2005, from http://www.teachingperspectives.com/PDF/summaries.pdf 


\section{NOTES}

